\title{
Energy Adaptive Glass Matter
}

\section{Alston ME*}

University of Salford Manchester, Salford, United Kingdom

\begin{abstract}
The critical aims of glass envelope design and development must be to enable measures upon glass buildings to prevent uncontrolled heating of the building surfaces, increase emissivity and the impacts of this heat conduction into the building interior spaces. Current glass envelopes depend upon hybrid facades, double skin glass facades; solar shading; passive solar energy systems (transparent insulation materials, solar glazing balconies) to reduce solar temperature gains upon this surface. The envelope performance is based upon measures in the reduction of heat conduction via the material that form its surface, to resolve the conflicts between services and fabric provisions (such as heating systems fighting cooling systems). New materials have been developed of increased performance to resolve this issue by product and component development. For example the integration of solar active elements within the glass panels. However glass building envelopes constructed in hot locations (where temperature are over 40 degrees) have the poorest lighting levels, as the needs to control thermal conduction and high energy consumption needs, to cool the building. These buildings are dependent upon artificial lighting and the reliance of HVAC systems.

The current technological development strategies for the building envelope is a static one, by this understanding materials are used without the ability to react to differing climatic zones or recognition of its global positioning. This is in contrast to the nature's adaptive functions, an adaptive bio-system in constant change to the influence of ambient temperature, solar radiation gain, exposure to wind and changing micro climatic variations. This reactive system is not transposed or reflected into the building envelope systems currently deployed. This non-reactive envelope gives little recognition of the response to climatic change or strategy variation to meet changing environmental situation. This approach is not reflected in nature, as these biosystems have the ability to adapt and control material composition.

Could the innovation and direction of a nature-inspired intelligent control of glass matter enable a new paradigm that will lead us in a direction to discover more adaptive systems in a dynamic response to our climate. To use the frontiers of science, in materials, in chemistry and physics, at a nanotechnology and biotechnology scale for greater control of thermal conduction.

Could the essence of nature forge evolution, in the creation of climatic responsive skins, by the principles of: material thermal facade behavior and thermal material temperature management. The employment of these objectives is to create material matter that is reactive in real-time to climatic change to enable thermal material management and regulation of its own material temperature. A dynamic skin that is responsive to the influence of ambient temperature, solar regulation gain as a adaptive biosystem.
\end{abstract}

Keywords: Heat conduction; Adaptive functions; Bio-system; Thermal material management and regulation; Reactive

\section{Introduction}

The emphasis on renewable energy and the increasingly reliance upon capturing and using energy from natural sources to meet primary energy demands of heating and cooling has gained significant momentum in the last decade. However Teske and Schafer [1] have indicated renewable energy only accounts for meeting $13 \%$ of the primary energy demand, $18 \%$ of electricity generation and $26 \%$ of heat supply. Today about $80 \%$ of the world's primary energy comes from polluting high-carbon fossil fuels such as coal, oil and natural gas, IEA [2]. The construction and life-cycle habitation of buildings in the EU 'would influence $42 \%$ of our final energy consumption, about $35 \%$ of our greenhouse gas emissions' [3]. COM 571 discusses the greater need for improved efficiencies in resources and energy use during the lifecycle, in enabling resource efficient buildings.

The Intergovernmental Panel on Climate Change (IPCC) [4] reports that currently energy-related greenhouse gas (GHG) emissions account for about $70 \%$ of total GHG emissions. Energy-related activities are currently the major contributors to climate change, Urban [5]. Since 1995 the energy consumption of the EU countries has risen by $11 \%$, to the value of $1637 \mathrm{Mt}$ of oil equivalent, from 1995 to
2006, Eurostat [6]. Studies indicate by Earth Trends [7] that buildings in Europe account on average for $36 \%$ of the energy use: the nonresidential sector accounts for $8.7 \%$ and the residential sector for $27.5 \%$ of the total.

Materials that form the surface areas of our buildings play a significant role, to create and modify environmental conditions for the activity within the spaces and this has a direct impact on primary energy demands. The requirements of heating, cooling, lighting and other appliances increase energy consumption and glass buildings in hot climates where temperatures are 40 degrees or higher, are vitally important in reducing energy demand in buildings. COM 639 [8]

*Corresponding author: Mark Alston, Lecturer in Construction Technology, University of Salford Manchester, Salford, United Kingdom, Tel: 44(0)161-2953834; E-mail: M.E.Alston@salford.ac.uk

Received January 17, 2014; Accepted February 19, 2014; Published February 26, 2014

Citation: Alston ME (2014) Energy Adaptive Glass Matter. J Archit Eng Tech 3 : 115. doi:10.4172/2168-9717.1000115

Copyright: (C 2014 Alston ME. This is an open-access article distributed under the terms of the Creative Commons Attribution License, which permits unrestricted use, distribution, and reproduction in any medium, provided the original author and source are credited. 
stated our cities will consume up to $80 \%$ of the energy needs and part of the problem in enabling smart cities strategy implementation. Greater 'efficient use of resources, affordable prices and innovative solutions are crucial to our long-term sustainable growth, job creation and quality of life.'[8] in the habitation and development of our urban centers.

During recent years different kinds of technological solutions have been developed in order to respond to the increasing requirements for improved energy-efficiency and sustainability. These technologies include hybrid facades, double skin glass facades; solar shading (lamellas or panels, high-performing glass); passive solar energy systems (solar glazing balconies) and active solar systems (solar collectors, photovoltaic modules). Other solutions have been investigated in relationship to glass facades electro chromic film and transparent materials. Electrochromic oxide film materials have electrical conductivity ions to enable changes in the optical properties of glass by the influence of a electric field and then return to the original state once the field is reversed. The employment of 'crystalline tungsten oxide film makes this surface infrared reflecting/adsorbing [9] creating a electrochromic that can self-color when exposed to sunlight. Transparent insulation materials of light transmitting aerogel (comprising of 95\% air) in nano-sized pores that inhibit heat transfer, have been developed. This material has thermal and optical properties to enable solar transmittance. However the transmitted light does have a tendency to scatter, as discussed by Torgal [10]. As a consequence of using the current technology, buildings consume significant level of energy [over its life cycle] due to the increased artificial lighting levels to compensate for the loss of natural lighting and the reliance of $\mathrm{AC}$ systems to cool the buildings. This reliance upon Artificial Lighting is one of the biggest causes of energy-related greenhouse gas emissions. The total lighting-related $\mathrm{CO}_{2}$ emissions were estimated to be 1900 million tons [Mt] in 2005, which was about $7 \%$ of the total global $\mathrm{CO}_{2}$ emissions from the consumption and flaring of fossil fuels [11,12]. On the other hand, according to US DoE figures [13], buildings may use between $15-35 \%$ of their energy consumption for lighting.

The development of these industrialized systems with possible integration of solar (thermal, $\mathrm{pV}$ ) and/or ventilation systems should in principle, enable integration of multiple functions into the façade elements. The current aims of the envelope performance is based upon measures in the reduction of heat conduction via the material that form its surface, to resolve the conflicts between services and fabric provisions (such as heating systems fighting cooling systems). New materials have been developed of increased performance to resolve this issue by product and component development for example the integration of solar active elements within the glass panels.

This resolution of building system performance as an optimizationall approach has uncertainty at its heart. As the level of energy consumption of a building depends upon the building typology and on the climate zone where it is located. In addition, the level of economic development in the area is also influential in shaping the energy use pattern. Energy demand in buildings brings together a range of complex relationships between the environment, individuals, and their perceptions of delighting comfort. The current technological development strategies for the building envelope is a static one, by this understanding materials are used without the ability to react to differing climatic zones or recognition of its global positioning. This is in contrast to the nature's adaptive functions, an adaptive biosystem in constant change to the influence of ambient temperature, solar radiation gain, exposure to wind and changing micro climatic variations. This reactive system is not transposed or reflected into the building envelope systems currently deployed. This non-reactive envelope gives little recognition of the response to climatic change or strategy variation to meet changing environmental situation. This approach is not reflected in nature, as these biosystems have the ability to adapt and control material composition.

As our cities core temperature continues to rise by the direct yearly solar radiation influence of our climate this is having an increasing impact upon an glass envelope systems. The total annual solar radiation falling on the earth is more than 7500 times the world's total annual energy consumption of $450 \mathrm{EJ}$. The annual solar radiation reaching the earth surface as presented by Kumar et al. [14] is approximately $3,400,000 \mathrm{EJ}$ and this is an order of magnitude greater than all the estimated non-renewable resources, including fossil fuels and nuclear.

Therefore the aim of this paper is to give a pathway of how; to prevent uncontrolled heating of the glass material surfaces and the impacts of this heat conduction, to enable optimization of a high emissivity glass material, as an adaptive dynamic skin by the objectives of:

i. Thermal conductivity matter behaviour exchange. (Material Adaptivity)

ii. Adaptive real-time performance to enable thermal heat exchange and thermal material management. (Glass Matter Autonomy)

\section{Material Adaptive Eco Systems}

Ecosystems upon this earth are evolving systems as they learn, defend, communicate, and protect themselves by the mechanisms of synergy to environmental influence. Nature uses biochemical mechanisms in a evolutionary perspective encapsulating multichemical compounds of action to give adaptable strategies. 'Plants and insects have been practicing and perfecting combinatorial chemistry on an evolutionary timescale' [15]. This synthesis of simulation of molecular behavior enables multiple paths ways embracing and involving chemicals material connectivity as a adaptive influence to climatic patterns. Plant use and embrace chemicals, Semi chemicals, to enable communication and pyrrolizidine alkaloid as defensive mechanisms in a response to global location/reference. The human body itself is a complex system of controlled mechanisms in response to changing situations to protect and control the human body by DNA programmable self-awareness, the ultimate intelligent material. These living multi-functional cells are information systems of chemical composition forming hierarchical structures as they have the:

- Ability to learn and adapt to changing circumstance.

- Self-regulation of thermal adsorption from nano scale components.

These systems are multifunctional, mechanical information systems that have the ability to adapt to changing circumstance by biological inspired engineering aims. This enables adaptive performance influence to change material composition by hierarchical controls of component material intelligence to give environmental adaptive functionality.

This is nature at a nanotechnology scale at work embracing adaptive functions to enable autonomous self-healing, intelligent surfaces, thermal management and hierarchical control of material matter itself. These functions are 'continually refining and adjusting shape, chemical and mechanical signaling' [16] for protection and adjustment to their environment. 
Could this approach of nature's adaptive functions, of biologically inspired intelligent materials enable procession of realtime reactive materials that form the skins of buildings. The current technological development strategies of glass facades are a static one, by this understanding materials are used without the ability to react to differing climatic zones or recognition of its global positioning. This is in contrast to the nature's adaptive functions, an adaptive biosystem in constant change to the influence of ambient temperature, solar radiation gain, exposure to wind and changing micro climatic variations. This reactive system is not transposed or reflected into the building envelope systems currently deployed. This non-reactive envelope gives little recognition of the response to climatic change or strategy variation to meet changing environmental situation. This approach is not reflected in nature, as these biosystems have the ability to adapt to changing environmental condition and control material composition.

\section{Adaptive System Performance}

Could our buildings move from mere material entities to becoming energy systems of adaptive performance. A dynamic skin, Figure 1, to exploit the functionalities and behavior of material science to act as a thermal energy adsorption system by the application of bio-logically inspired systems by the principles of:

- Capture in enabling thermal transfer.

- Control to regulate and enable thermal management of matter.

\section{Cyclic behaviour}

The abstract, Figure 1, indicates the sequential processes of heat transfer as a behavioral adaptive system. The aim is to set the thermal conductivity adsorption levels of the composite glass core material, by the determination of the steady-state temperature of the skin. This sets the datum point reference for the intelligent control sensoring and actuation systems through the manipulation of fluidic flows within a network as a cyclic behavior model to remove and influence material skin conduction rates.

- Setting a datum point for glass steady state temperature.

- Thermal energy inputs into the glass skin through, 'solar radiation gains $4,42 \mathrm{GJ} / \mathrm{m}^{2}$ year' (Trees [17] European continental climate influence, example) creates temperature raise by city micro-climate and IR wavelength.

- Glass skin heat IR conduction.

- Fluidic medium acts as the absorber of thermal energy transfer by a fluidic network at a molecular thermal conduction level.

- Manipulation of fluidic behavior in micro fluidic network in a active manner by sensor data feeds and network flow actuation controls. Enables temperature skin reduction in a active responsive manner for thermal energy removal and transfer.

- This removal of energy enables cooling of the glass material to revert to its datum starting point, steady state temperature. This is a cyclic action of molecule's temperature regulation, as a repeatable action for thermal energy adsorption. Rates of thermal adsorption are dependent upon the time of day, wind exposure, orientation and city thermal temperatures.

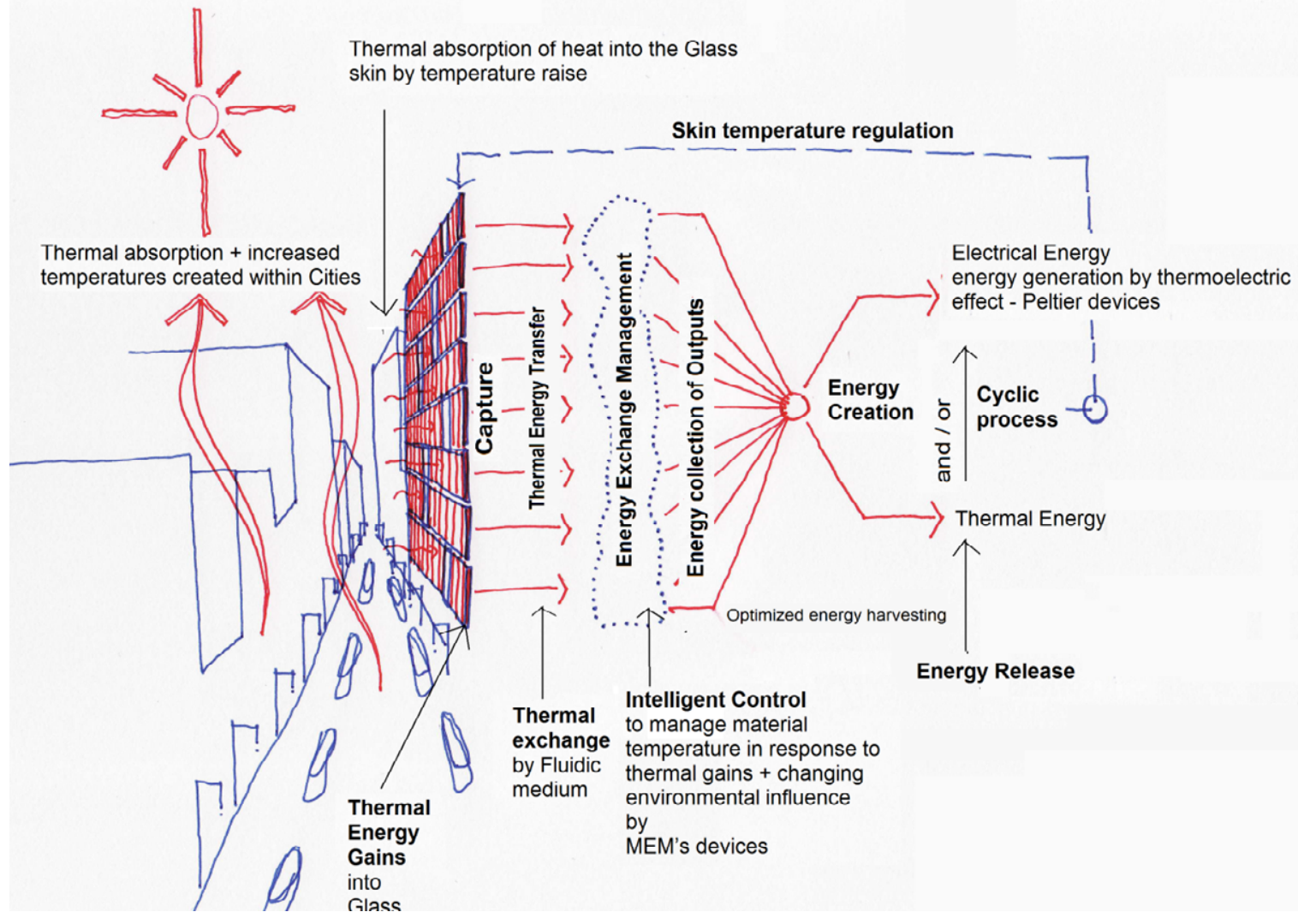

Figure 1: Abstract of intelligent surface skin. 
- Transfer of energy from the fluidic network into thermal storage or electrical energy generation by Peltier devices for energy unloads processes of the micro fluidic network.

This cyclic behaviour sequential process creates a multi-functional system that responds to localized environmental conditions by the regulation of its own material temperature, as an adaptive dynamic skin by the objectives of:

i. Thermal conductivity matter behaviour exchange. (Material Adaptivity)

ii. Adaptive real-time performance to enable thermal heat exchange and thermal material management. (Glass Matter Autonomy)

\section{Material Adaptivity}

Aim: Thermal conductivity matter behaviour exchange-The creation of a glass composite structure by insertion of a domain between two glass plates. This medium/domain contain micro channel networks within its structure that can influence its surrounding by fluidic flow behaviour.

The creation of this vascular network is similar to that of the human body vascularization system, to enable control by delivery of nutrients, removal of waste, temperature regulation and damage repair by a functional chemical fluid. These microvascular volume filled networks or matrixes enables thermal exchange interactions to material or regions within a material. This concept and application of it could enable active matter control by regulating thermal temperature by the deployment of active cooling microvascular systems continuously circulating a fluid into, through and out of the matrix in order to adsorb and remove excess heat. Microvascular volume filled networks could give glass the innovation for active cooling and energy generation to set performance functions, in regulation of surface glass temperatures. An example of this form of application is indicated in Figure 2.

Design and evaluation of the performance function efficiency of the microvascular $3 \mathrm{~d}$ capillary network is obtained by using a multiobjective generic algorithm by sequence optimization [18]. These genetic exchange algorithmic optimization solutions are achieved by the application of fittest function objectives. These fittest function aims create progressive modifications by re-combinations to create new solutions. This solution, generations, will compete and learn as they interact to form generative behaviours. 'Careful observations of successive structural modifications generally reveal a basic set of structural modifiers or operators, repeatable actions of these operators yield the observed modifications sequences' [19]. This enables repeatable geometry microvascular creations to determine future solution network efficiencies by understanding of boundaries
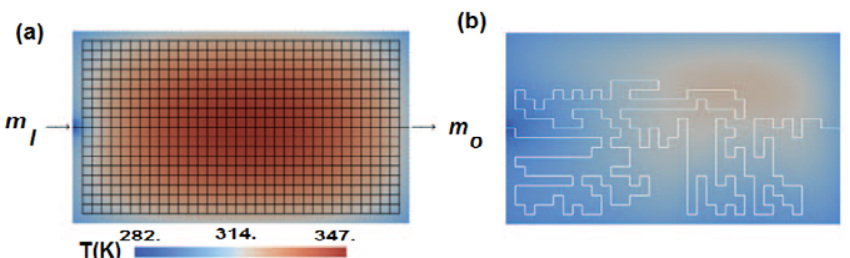

Figure 2: (a) A grid form microvascular network is used as an initial starting configuration with a uniform heat source is applied to a surface. (b) The development of the network by performance optimization, to create the microvascular network (indicated in white capillary channels). To enable active cooling of the surface material temperature, achieved by fluidic flow rates. (taken from S.R. Olugerbelefloa et al. [18]).

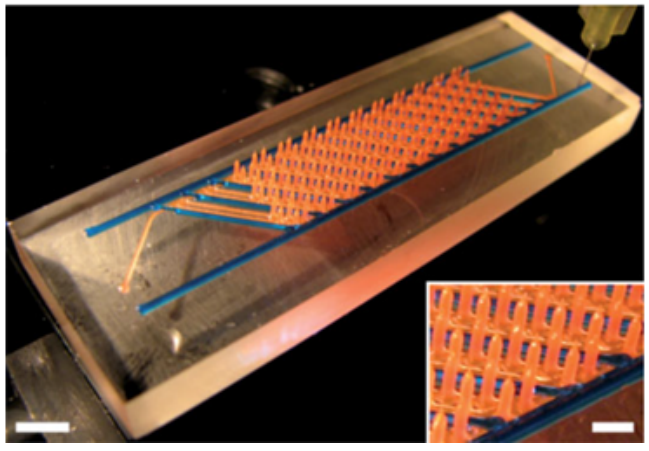

Figure 3: Micro channel vascular networks formed by 330-100 $\mu \mathrm{m}$ capillaries within an epoxy matrix formed by wax based inks.(taken from Hansen et al. [21]).

constraints for optimization performance cooling objectives. This genetic algorithm gives optimization for microchannel functionality within a domain to enable optimized flow efficiency and thermal fluidic adsorption for skin surface temperature regulation.

However the network microcapillary channel density is a correlation to optimization functionality, as this has effects upon structural integrity of the material domain body. Hence performance is a balance to maximize the benefit of the network to minimizing the negative structural integrity impacts. 'Most microvascular networks designs are constrained by the choices of fabrication methods and materials. 'Olugerbelefloa et al. [18]. Forming this microvascular network within a domain could be achieved by PDMS, epoxy matrixes, (Figure 3).

This sealed capillary network, Figure 3, was created to enable autonomous self-healing of structural materials that have suffered from crack plane damage and reduced structural integrity. The isolated and independent three dimensional vascular networks contains within the capillaries fluidic filled epoxy resin (orange) and hardener (blue). In the event of crack plane damage to the matrix body the interconnecting networks, orange and blue, acts as catalytic chemical triggers, as demonstrated by White et al. [20] to enable crack proximity selfhealing cycles to commence.

The construction of this 3 dimension network geometries was achieved by the advances in 'dual ink deposition and vertical ink writing using microcrystalline wax and mineral oil. The network was constructed by independently deposited two fugitive organic inks to construct the desired interpenetrating, yet isolated, microvascular network' Hansen et al. [21,16]. Once constructed the network was embedded into a epoxy matrix with the wax based inks being removed by temperature liquefaction and vacuum. Forming these microvascular network within a domain body can also be achieved by CNC machines that 'are capable of producing feature sizes on the order of tens of microns, Chen [22] or the application of micromachining technology to fabricate the network 'microchannels in a layer by layer fabrication approach' Saxena [23] at a sub-micron resolution. However the innovation of nano-materials, for example the potential of graphene could be the innovation of network mediums.

Graphene is a nano-material made of carbon atoms and has exceptional properties of being transparent, lightweight and an excellent heat conductor that could replace PDMS and epoxy as a medium. This nano-material could enable the development of a conductive resiliently strong material, enabling heat transfer of this translucent material 
and within its structure the formation of a microvascular network for the encapsulation of fluids. The formation of this medium could be undertaken by the advancement of nanotechnology to mechanically assemble the carbon crystallites one by one to create the desired sequence of planes of the graphene structure itself. Geim [24] has pointed out graphene could be used to create 'complex devices with various functionalities can be constructed plane by plane with atomic precision' (Figure 4).

The Wyss Institute at Harvard University has conducted research into vascular microfluidic windows by the application of applying polydimethylsiloxane. This PDMS material contained within its structure a series of capillary $100 \mu \mathrm{m}$ high channels patterns forming a network to enable fluidic water flow rates. This PDMS medium was then inserted between two glass plates to create the glass composite structure. A uniform heat load of 35 degrees was then applied to a surface and measurements taken, to analysis the effects of thermal adsorption transfer. Various flow rates were introduced to measure the impacts and surface cooling results by thermal heat exchange rates, to adsorb and transfer this heat into the fluid, water, to enable heat capture and removal.

Variant flow rates assessed: $0.2 \mathrm{~mL} / \mathrm{min}, 2.0 \mathrm{~mL} / \mathrm{min}, 10 \mathrm{~m} / \mathrm{L} /$ min. However as discussed by Wheedon and Hatton [25] the results concluded the effectiveness was dependent upon input water temperature to act as the absorber of thermal energy transfer. Significant temperature reduction was achieved at medium and high flow rates with water applied at 0 degree celsius achieved dramatic response mean temperature over time, with low flow rates being ineffective to control thermal temperature gains. The results confirmed the effectiveness of the microchannel in actively enabling thermal adsorption and exchange however it was the fluidic material itself that can reduce and diminish thermal energy transfer.

Could however these networks give advancement of skin antonymy by distribution of active chemical fluids through the exploration and maximization of thermal exchange by temperature gain, natural convection, 'latent heat release and internal thermal conductivity of Agbossou et al. [26], by the application of nanofluidics.

\section{Nanofluidics}

Research has been undertaken to enable innovative way for improving thermal conductivity of a fluid by the suspension of metal or metal oxide nano particles and carbon nanotubes, smaller than 100 $\mu \mathrm{m}$. The resulting mixture is referred to as nanofluids that possesses substantially larger thermal conductivity compared to that of base

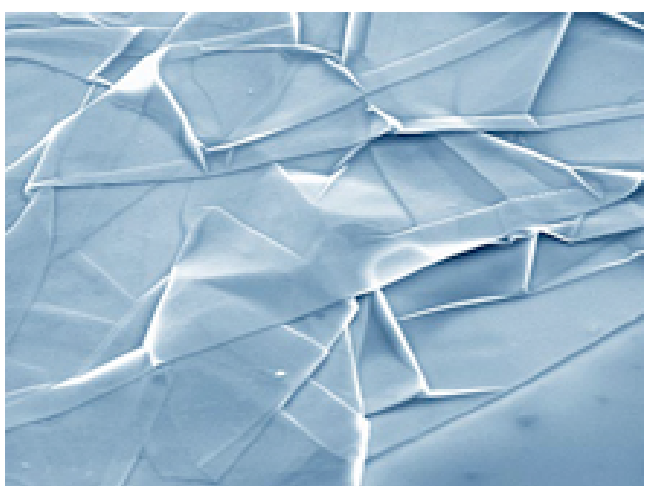

Figure 4: Scanning-electron microscope image shows a crumpled graphene sheet of the single-atom-thick material. (taken from University of Manchester). fluids itself, was researched by Yu-Dong et al. [27]. Nanofluidics of active heat absorbing fluids within microvascular networks could give optimization of network efficiency for surface cooling and temperature regulation. The employment of chemical composition into fluidic networks of nanofluid chemical particles can increase energy absorbing rates. This creation of a chemical 'designer molecule approach synthesizing the material Watson' [28] would give thermal exchange by chemical integration enabling greater molecular surface heat exchange. Experimental studies have shown that the effective thermal conductivity increases remarkably. This is also associated with enhancement of other transport properties, for example. Viscosity, specific heat and diffusivity. Water is utilized as a main suspension medium because of its favorable thermal properties and costs. However, it has low energy density; therefore, nanoparticles can increase viscosity due to their high latent heat of transition, high energy densities [29]. Nanoparticles will also help to resolve the impacts of the fluctuations in the solar energy input, by the retention of energy for distribution within the vascular network for energy unload processes.

- The application of nanoparticles presents a enhancement of thermal conductivity, heat transfer coefficient and viscosity as determined by the heat transfer properties:

- The suspended nanoparticules increase the surface area and heat capacity of the fluid. fluid.

- The suspended nanoparticles increase thermal conductivity of the

- The interactions and collision among particles, fluid and the flow passage surface are intensified as well as the mixing fluctuation and turbulence.

- The dispersion of nanoparticles fattens the transverse temperature gradient of the fluid.

The understanding of the physical properties and composition behaviour of specific heat of nanofluids was discussed by Cellura et al. [30] as being adaptable to climatic variation response to external temperature range. This would enable a global perspective outlook. This response is the approach of nature, to adsorb energy for warm and heat, to give and enable cooling to control and stabilization of temperature in a response to climatic influence.

\section{Glass Matter Autonomy}

Aim: Adaptive performance to enable thermal management of materials, by the influence of active intelligent manipulation control of microfluidics.

Adaptive level intelligence is needed to react as the human body does to control and influence surrounding tissues by the vascularization system of self-regulation. This vascularization system contains nanoscale components of multi-functional, mechanical information systems for cellular vascular autonomy.

Therefore active microvascular manipulation is needed by the employment of hierarchical measures by sensors and actuators, controlled by programmable algorithms to enable collective control of the system. This biologically inspired system will actively control the heat absorbing microvascular network of continuous circulatory fluid flow, to enables adsorption and thermal heat transfer to maximize network functionality.

The employment of devises called MEM's (Micro electromechanical) focusing upon the development of miniaturized 
devices, enable opportunities to develop high-performance materials for the fabrication of mechanically flexible electronic systems built on the scale of millionths of a meter. These systems have been 'advanced by semiconductor processes to create sensors, accelerometer, flow sensors and actuators have been widely demonstrated. [31].

Pressure sensors to monitor, measure and enable subsequent active actuation measures of fluidic flow rates are in the process of development by the application of Nano electromechanical system (NEM's), DNA protein sensors. Lou et al have created a pressure sensor by using silicon nanowires (SiNWs) based sensor design. This (SiNWs) diaphragm sensor has a diameter of $200 \mu \mathrm{m}$, with a high pressure sensitivity of $0.6 \% \mathrm{psi}^{-1}$ and the capability to sustain pressures above 330 psi. This NEM miniaturized pressure sensor could be used to monitor the microvascular circulatory system in assessment of fluidic flow conduction rates. Real-time information feed on the status of the system by MEM's devices could be inserted into the vascular network to enable monitoring. These transparent, flexible display devices have been investigated by, Koo et al. [32]. The research team have developed an integrated, thermal stable LED with power source encapsulated in two sheets PDMS with a net thickness of $1 \mathrm{~mm}$. The research undertaken by Koo et al could enable innovation of thin-film nanogenerators and thermoelectric devices.

Monitoring of the system performance is critical to enable sensor real-time data information feed in order to make autonomous adjustment to actuators for manipulation of microfluidic flow rates. The mechanisms for automatous functionality of the system to give surface temperature regulation would be a algorithm. This would act as a skin management system to enable strategies to focus upon thermal energy load-unload processes as a cyclic action, Figure 1. This load shift enables removal of energy from the microvascular system to regain steady state temperatures to give self-programmable thermal conductivity management.

However the system functionality is intrinsically linked to climatic influence and response. Therefore glass composite material system must be able to "learn and apply" different strategies to meet various climatic zones. This will enable a climatic setting for the creation of a behaviour model for the management system. The development of a climatic model will enable reactive behaviour changes by the comprehension of its global climatic location and positioning. The understanding of the climatic behaviour model will be dependent upon the climatic classification in order to set primary data functions. Climate classification will determine and give the back ground knowledge for understanding longitude/latitude effects.

The understanding of the thermal facade behaviour of buildings and its implications on energy performance has been research through SUSREF, by VTT [33]. This research enabled a climatic classification analysis system to be developed. Climatic categorization are:

Climatic categorization are:

$\mathrm{Cfb}$-temperate without dry season, warm summer;

Cfbw—temperate without dry season, warm summer and windy;

Csa-temperate with dry, hot summer;

$\mathrm{Dfb}$-cold, without dry season and with warm summer; and

Dfc-cold, without dry season and with cold summer.

\section{Discussion}

The creation of microvascular volume filled fluidic networks enables thermal heat exchange influence in materials that surround the vascular capillary system. This influence enables regulation of thermal conductivity by fluids acting as absorbers of thermal energy by manipulation of the circulatory flows rates through the network, as a vascularization system has been demonstrated. The performance efficiency of the vascular networks geometry design, obtained by pre-programmed genetic algorithms [18], gives assessment of the network ability to adsorb thermal energy input by pre-programmable logic patterns, enables optimized flow efficiency to manipulate surface temperature load processes. The innovation of nanomaterials, graphene, could give containment of the vascular networks in a resiliently strong and translucent material for performance advancement of microvascular geometry could be utilized for the progression of vascular domain materials.

This coupled with improving thermal conductivity of heat transfer by active heat absorbing fluids within the vascular network, enables optimization of the network efficiency for temperature regulation. This nanofluid design approach could enable greater molecular surface heat exchange influence.

Manipulation of the fluidic flow rate of thermal absorbing fluids can be achieved by sensor and actuators for glass matter autonomy. This vascularization systems is similar to that of the human body to influence surrounding tissues by adaptive, self-regulating living cells. MEM's, incredibly tiny devices often built on the scale of millionths of a meter, act as the monitors of the system performance for thermal management to enable subsequent reactive, real-time, changes to give thermal energy unload processes as a cyclic sequence of actions (Figure $1)$.

Principles of micro-fluidic flows in vascular networks is however a concern, as the whole skin facade could not be treated as one entity, as the vascular network will have a resistance to flow and this could be considerable. Hence the pumping pressures needs to be controlled, as any energy gains from thermal regulation of the skin, could be outweighed by the energy needed to give pumping power through the network.

However the facade could be treated as a network of glass composite modules, (Figure 5) to form the overall envelope skin entity. These glass composite modules could create the overall envelope as a modular system. This modular system could enable interface connections between each other to create a cellular group of three units, to form a cell group.

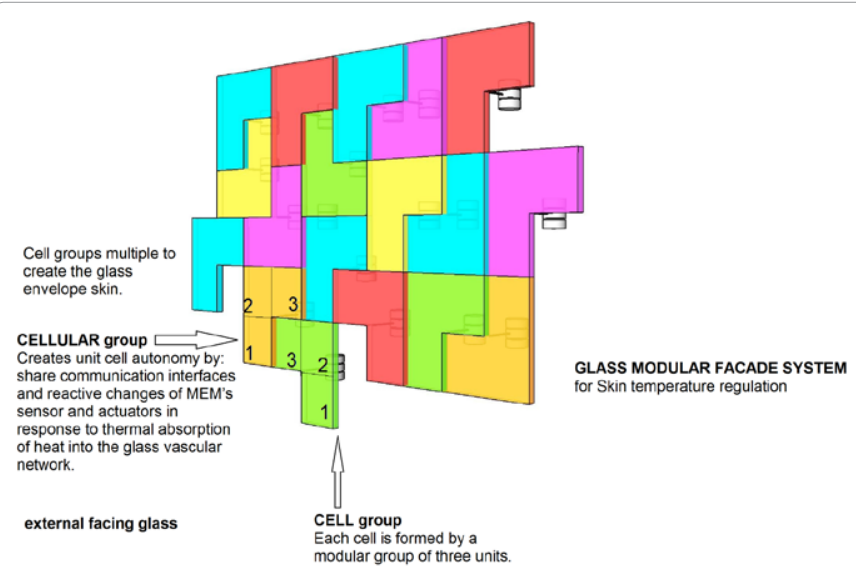

Figure 5: Abstract model of multiple cell groups. 


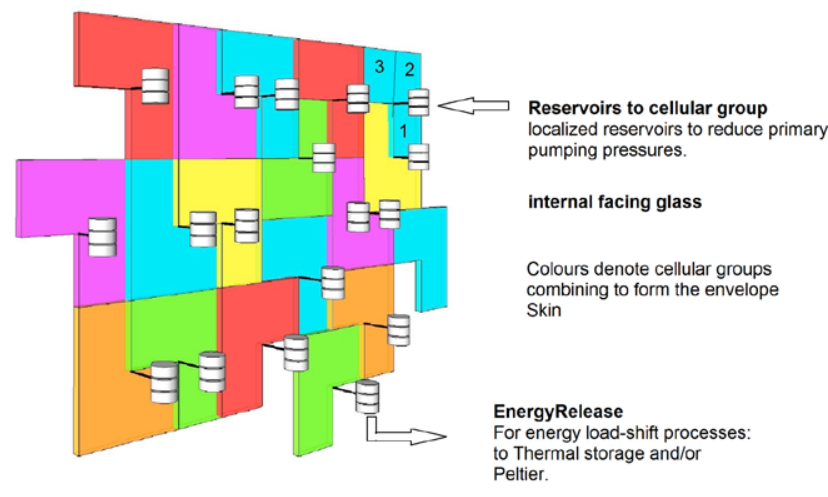

Figure 6: Abstract model of localized reservoirs.

This cell group could share data communication feeds of sensors, actuation systems and tank reservoirs to act as a single unit entity, to give cellular autonomy to that cell group to learn and apply reactive aims in response to changing thermal conductivity levels. These cell groups would multiple to form the overall envelope skin for the building (Figure 6). Nestle [34] discussed the breakdown of the facade into cellular groups would enable reduction of primary pumping pressures. This would be achieved by the creation of localized reservoirs, serving the cellular group unit to enable optimization of pumping power and energy load-shift process.

\section{Conclusion}

Nature has evolved mechanisms to influence materials by the application of measures to change material composition in relationship to the environment. This multi-functional thermal reactive system is a blue print that has evolved on a evolutionary perspective.

Could this approach of nature's adaptive functions, of bio-logically inspired aims, enable procession of real-time reactive engineering materials. To move our buildings from mere material entities to becoming energy systems of adaptive performance. A dynamic response, to exploit the functionalities and behaviour of material science to act as a thermal energy adsorption system by the application of bio-logically inspired engineering principles of:

Thermal conductivity matter behaviour exchange and thermal management of materials, by the influence of active intelligent manipulation control of microfluidics. These principles, of surface material temperature regulation, could change our buildings into climatic modifiers by the dehumidification of material surface temperatures, for energy harvesting to enable real time thermal conduction performance response.

This adaptive skin (Figure 1) is a dynamic system, of reactive responses to environmental influence by the understanding of the changing behaviour of thermal conductivity levels. This regulation of thermal transfer, to prevent uncontrolled heating of building interior spaces, will reduction the increasing reliance of primary energy demands. The formation of cell units as a facade system (Figures 5 and 6) to create cellular group autonomy, will enable hierarchical level intelligence controls of facade panelized assemblies, using microfluidics for precise behaviour control and manipulation of fluids by the application of micro-thermal technological engineering principles.

It is expected three-quarters of the world's population will live within our cities. This migration and increasing expansion in human habitation, is the creation of energy hungry cities, detached from our ecosystems and become a destroyer of it. Our cities are the major contributor to greenhouse gas production. Cities are complex energy systems with an ever changing matrix of human activities and environment affects.

The creation of intelligent surfaces could create buildings working as clusters to influence the environment .To change our cities into living organisms, adsorbing energy, to reduce intensifying heat island temperatures within the city core. To truly create eco-cities of the future at the forefront of low carbon reduction, we must embrace new bio-inspired engineering aims, by applying new concepts in material engineering to form our building surfaces to enable transformation.

\section{References}

1. Teske S, Krewitt W, Schäfer O, Simon S, Wina G, et al. (2008) Energy $[R]$ evolution: a sustainable world energy perspective. Renewable Energy World 37: $5764-5775$

2. IEA (2002) Electricity in India: Providing Power for the Millions. Published by OECD.

3. Brussels, COM 571 (211) Communication from the commission to the European Parliament, the council, the European economic and Social committee and the committee of the regions. Roadmap to a Resource Efficient Europe.

4. IPCC (Intergovernmental Panel on Climate Change) (2013) Climate Change 2013. Fifth Assessment Report of the Intergovernmental Panel on Climate Change.

5. Urban F (2009) Climate-Change Mitigation Revisited: Low-Carbon Energy Transitions for China and India. Development Policy Review 27: 693-715.

6. Eurostat. Eurostat press office, 2006.

7. Earth Trends (2005) Terra Viva! Geo Data Guide.

8. Brussels, COM 639 (2010) Communication from the commission to the European parliament, the council, the European economic and Social committee and the committee of the regions. Energy 2020 A strategy for competitive, sustainable and secure energy.

9. Granqvist CG (1995) Handbook of Inorganic Electrochromic Materials. Elsevier, Amsterdam.

10. Paceco-Torgal F, Diamanti MV, Nazari A, Granqvist CG (2013) Nanotechnology in eco-efficient: Materials, processes and applications. Woodhead Publishing Series in Civil and Structural Engineering 43.

11. Annual Energy Outlook (2007) U.S. Energy Information Administration, Washington DC

12. World Energy Outlook (2006) International Energy Agency, France.

13. U.S. Department of Energy (2006) Energy Demands on Water Resources.

14. Kumar A, Kumar K, Kaushik N, Sharma S, Mishra S (2010) Renewable energy in India: Current status and future potentials. Renewable and Sustainable Energy Reviews 14: 2434-2442.

15. Page SW (2004) Advances in Insect Chemical Ecology. Bull World Health Organ 82: 955

16. Chen PY, Joanna MK, Meyers MA (2012) Biological materials: Functional adaptations and bioinspired designs. Progress in Materials Science 57: 14921704

17. Trees (2007) Intelligent Energy-European Programme, Association pour la Recherche et le Développement des Méthodes et Processus Industriels.

18. Olugebefola SC, Aragon MA, Hansen CJ, Hamilton A, Wu W, et al. (2010) Polymer Microvascular Networks Composites. J Composite Materials 44: 25872603

19. Holland J (1992) Adaptation in Nature and Analysis with application to artificial systems. An introductory to Biology, Control and Artificial Intelligence, Bradford books.

20. White SR, Scottos NR, Geubelle PH, Moore JS, Kessler MR, et al. (2001) Autonomic healing of polymer composites. J Nature 409: 794-797. 
21. Hansen CJ, Wu W, Toohey KS, Sottos NR, White SR, et al. (2009) Self-healing Materials with Interpenetrating Microvascular Networks. Advanced Materials 21: 4143-4147.

22. Chen S (2008) Fabrication of High-density Micro-holes by upward batch micro EDM. J Micromech Microeng 18.

23. Saxena L, Agrawal A, Joshi S (2009) Fabrication of Microfilters Using Excimer Laser Micromachining and Testing of pressure drop. J Micromech Microeng 19.

24. Geim AK (2012) Graphene prehistory. Physica Scripta T146.

25. Adaptive Architecture (2011) An International Conference, Building Centre, London.

26. Agbossou A, Zhang Q, Sebald G, Guyomar D (2010) Solar micro-energy harvesting based on thermalelectric and latent heat effects. J Sensors Actuators A: Physical 163: 277-283.

27. Liu YD, Yue Z, Ming WT, Xiao SZ (2009) Experimental study of therma conductivity and phase change performance of nanofluids PCMs. J Microfluid Nanofluid 7: 579-584
28. Watson J, Director Global Research, Government advisor, Arup. Personal communication in 2009.

29. Abhat A (1983) Low-temperature latent heat thermal storage: heat storage materials. Solar Energy 30: 313-332.

30. Cellura M, Ciulla G, Brano VL, Marvuglia A, Cellura AO (2008) A Photovoltaic panel coupled with a phase changing material heat storage system in hot climates. $25^{\text {th }}$ Conference on Passive and Low Energy Architecture.

31. Lou L, Zhang S, Park WT, Tsia JM, Kwong DL, et al. (2012) Optimization of NEMS pressure sensors with a multilayered diaphragm using silicon nanowires as piezoresistive sensing elements. J Micromech Microeng 22.

32. Koo M, Park K, Lee SH, Suh M, Jeon DY, et al. (2012) Bendable inorganic thinfilm battery for fully flexable electronic systems. J Nanoletter 12: 4810-4816.

33. VTT, FP7 ENV (2012) Energy Efficient Façade System for Building Retrofitting

34. Nestle N (2011) Research scientist, BASF \& Junior professor in Vorgriffsregelung: Personal communication.
Citation: Alston ME (2014) Energy Adaptive Glass Matter. J Archit Eng Tech 3: 115 . doi:10.4172/2168-9717.1000115
Submit your next manuscript and get advantages of OMICS Group submissions

Unique features:

- User friendly/feasible website-translation of your paper to 50 world's leading languages

- Audio Version of published paper

Digital articles to share and explore

Special features:

300 Open Access Journals

25,000 editorial team

21 days rapid review process

Quality and quick editorial, review and publication processing

Indexing at PubMed (partial), Scopus, EBSCO, Index Copernicus and Google Scholar etc

Sharing Option: Social Networking Enabled

- Authors, Reviewers and Editors rewarded with online Scientific Credits

Better discount for your subsequent articles

Submit your manuscript at: http://www.editorialmanager.com/acrgroup/ 